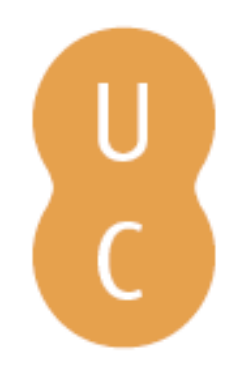

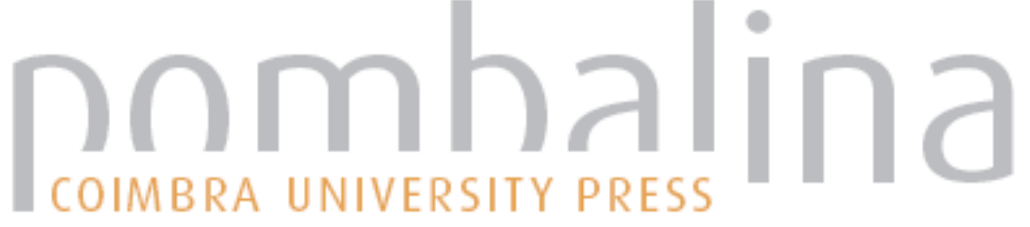

\section{Por entre brasas e fumaças: uma abordagem geográfica}

Autor(es): $\quad$ Lourenço, Luciano; Valencio, Norma; Scopinho, Rosemeire

Publicado por: Imprensa da Universidade de Coimbra; RISCOS - Associação

URL

persistente: URI:http://hdl.handle.net/10316.2/34910

DOI: $\quad$ DOI:http://dx.doi.org/10.14195/978-989-96253-3-4_110

Accessed : $\quad$ 26-Apr-2023 11:06:16

A navegação consulta e descarregamento dos títulos inseridos nas Bibliotecas Digitais UC Digitalis, UC Pombalina e UC Impactum, pressupõem a aceitação plena e sem reservas dos Termos e Condições de Uso destas Bibliotecas Digitais, disponíveis em https://digitalis.uc.pt/pt-pt/termos.

Conforme exposto nos referidos Termos e Condições de Uso, o descarregamento de títulos de acesso restrito requer uma licença válida de autorização devendo o utilizador aceder ao(s) documento(s) a partir de um endereço de IP da instituição detentora da supramencionada licença.

Ao utilizador é apenas permitido o descarregamento para uso pessoal, pelo que o emprego do(s) título(s) descarregado(s) para outro fim, designadamente comercial, carece de autorização do respetivo autor ou editor da obra.

Na medida em que todas as obras da UC Digitalis se encontram protegidas pelo Código do Direito de Autor e Direitos Conexos e demais legislação aplicável, toda a cópia, parcial ou total, deste documento, nos casos em que é legalmente admitida, deverá conter ou fazer-se acompanhar por este aviso.

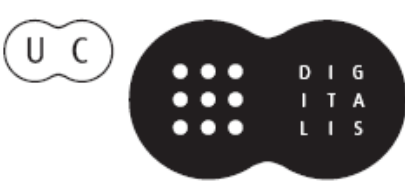



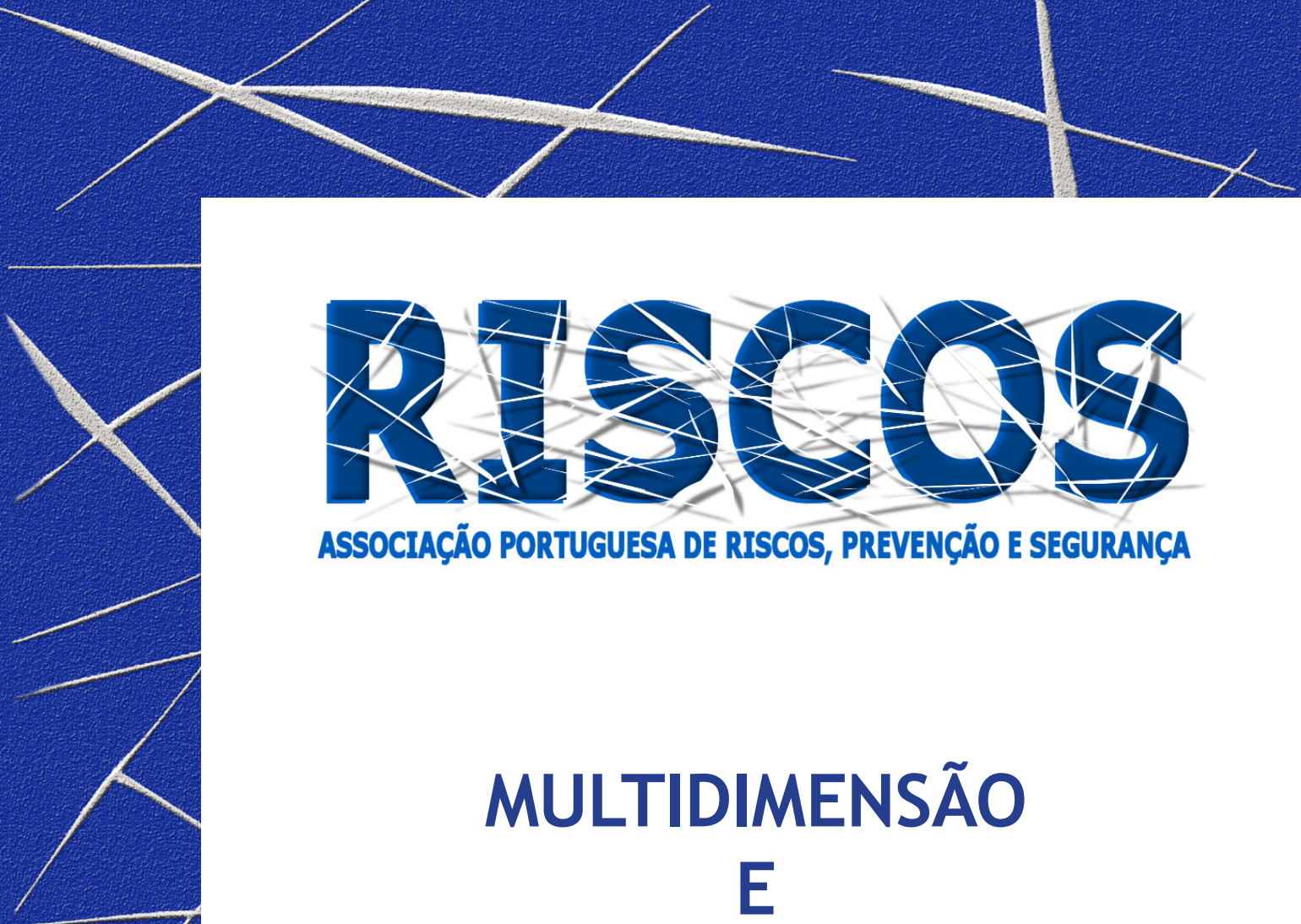

ASSOCIAÇÃO PORTUGUESA DE RISCOS, PREVENCCÃO E SEGURANÇA

MULTIDIMENSÃO

E
TERRITÓRIOS DE RISCO

III Congresso Internacional

I Simpósio Ibero-Americano

VIII Encontro Nacional de Riscos

Guimarães

2014 


\title{
POR ENTRE BRASAS E FUMAÇAS: UMA ABORDAGEM GEOGRÁFICA
}

\author{
Luciano Lourenço \\ Departamento de Geografia e CEGOT, Faculdade de Letras da Universidade de Coimbra \\ luciano@uc.pt \\ Norma Valencio \\ Programa de Pós Graduação em Sociologia,Universidade Federal de São Carlos \\ Programa de Pós-Graduação em Ciências da Engenharia Ambiental, Universidade de São Paulo \\ normaf@terra.com.br \\ Rosemeire Scopinho \\ Departamento de Psicologia e NUESTRA, Universidade Federal de São Carlos \\ scopinho@ufscar.br
}

\begin{abstract}
RESUMO
Apresenta-se a abordagem geográfica que esteve na base dum projeto, desenvolvido na Serra do Açor (Portugal), por investigadores provenientes de três diferentes núcleos de investigação científica, pertencentes a universidades brasileiras e portuguesas, e também a três áreas científicas distintas (geografia, sociologia e psicologia social), que procuraram caracterizar, em termos sociais, as consequências deixadas pelos incêndios florestais na vida dos aldeões. Assim, identificaram-se os grandes incêndios que afetaram a serra do Açor e explicitam-se os critérios que levaram à escolha das áreas-amostra onde foi desenvolvido o estudo: oito localidades, todas elas afetadas, direta ou indiretamente, por incêndios florestais, umas há mais tempo e outras mais recentemente.

Em comum, apresentam a característica de todos esses incêndios permanecerem bem gravados na memória social das comunidades, guardada pelos moradores idosos, que constituem a população dominante destas aldeias.

Palavras-chave: Serra do Açor, incêndios florestais, memória social, idosos.
\end{abstract}

\section{Introdução}

Partindo da cartografia obtida através de trabalho de campo, desenvolvido nos últimos anos, em municípios do alto do distrito de Coimbra, bem como de análise cartográfica e documental, designadamente dos Planos de Defesa da Floresta contra Incêndios (Nacional e Municipais), foi possível promover nova investigação, de base qualitativa e de caráter sociológico, no início do período crítico de incêndios do ano de 2013, que decorreu em três desses municípios, tendo permitido desenhar um panorama geral das especificidades locais que envolvem a problemática da floresta e dos incêndios florestais na área de estudo.

Com efeito, a cartografia dos incêndios florestais ocorridos nas últimas cinco décadas, permitiu identificar as localidades mais suscetíveis a incêndios no alto distrito de Coimbra, de entre as quais foram selecionadas oito aldeias, em três concelhos diferentes, para realizar entrevistas não só aos moradores idosos, mas também aos agentes envolvidos na prevenção e combate a incêndios florestais desses municípios.

Depois, em resultado do contacto com as autoridades autárquicas, foi possível aceder aos documentos oficiais de planificação das ações oficiais de defesa da floresta contra incêndios que, em cada um desses municípios, são aplicadas no terreno.

\section{Localização da área de estudo}

A área de estudo, inicialmente prevista, compreendia quatro municípios do alto distrito de Coimbra, pertencentes à serra do Açor, por serem aqueles que possuem a maior área ardida do 
distrito. Todavia, depois, por falta de financiamento do projeto, os investigadores foram forçados a reduzir a área a tratar, tendo eliminado o concelho de Pampilhosa da Serra, por ser aquele que se encontrava mais afastado da base logística, a sede dos investigadores, apesar de ser o mais afetado por grandes incêndios florestais.

A serra do Açor localiza-se no sector intermédio da cordilheira central portuguesa, mais precisamente entre as serras da Lousã (1205m), a ocidente, e da Estrela (1993m), a oriente, as quais, no seu conjunto, constituem o mais importante conjunto montanhoso português e dividem Portugal em dois domínios climáticos diferentes: o Norte, mais atlântico, e o Sul, marcadamente mediterrâneo. Por sua vez, a serra do Açor é cortada pelo rio Ceira, que se desenvolve no sentido este-oeste, dividindo-a em dois blocos: o setentrional, que alcança $1342 \mathrm{~m}$, em São Pedro do Açor, e o meridional, a sul do rio Ceira, que culmina ainda a maior atitude, $1418 \mathrm{~m}$, no Picoto de Cebola.

Como sabemos, o relevo dificulta a atuação dos meios de combate às frentes de chamas, quer pelos declives acentuados que têm de vencer, quer pela sinuosidade das estradas que retardam a primeira intervenção.

Como nesta fase o tempo cronológico é um elemento crucial, se, porventura, se deixa que o incêndio evolua e passe a ser grande, depois o seu controle é bem mais difícil, como tem sucedido, com demasiada frequência, nestas áreas montanhosas, onde se localizam as aldeias estudadas (fig. 1).

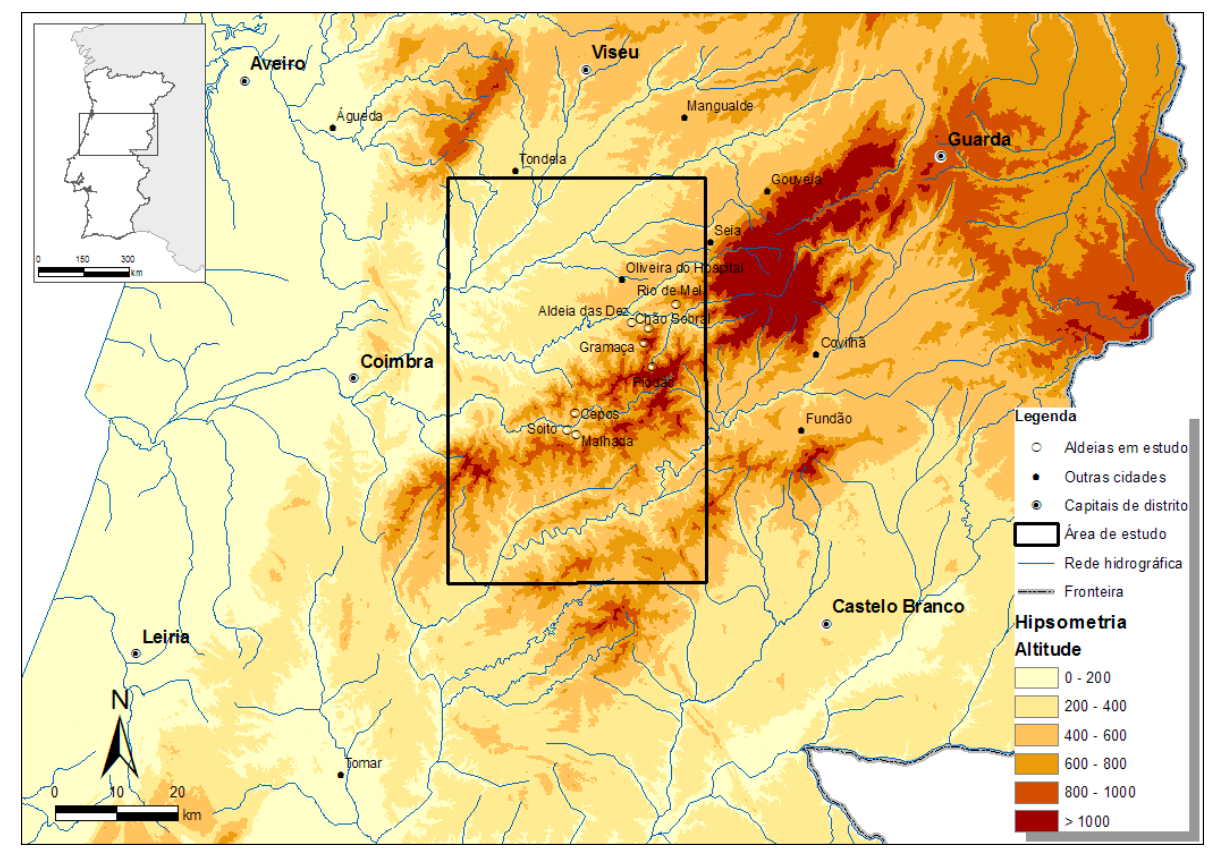

Fig. 1 - Esboço hipsométrico e de localização da área de estudo, com referência às oito aldeias investigadas.

(Cartografia elaborada por Sofia Bernardino, adaptada da produzida pela Agência Portuguesa do Ambiente e pela Direção-Geral do Território). 


\section{Os incêndios florestais no período pós 1974 e os critérios de seleção das aldeias}

A enorme extensão de áreas queimadas pelos incêndios florestais nas serras da Cordilheira Central portuguesa e, em particular na serra do Açor, acentuou-se a partir de meados dos anos setenta do século passado, ou seja, depois da chamada "Revolução dos Cravos" ou de "Abril de 74", pelo que, no período compreendido entre 1975 e 1985, alguns municípios da serra do Açor viram a sua floresta devastada por grandes incêndios que dizimaram mais de $100 \%$ dessa área florestal, dado que alguma dela foi queimada mais do que uma vez. Assim, apenas numa década, de que já pouco se fala, a superfície florestal do concelho da Pampilhosa da Serra ardeu quase duas vezes (180,04\%), em Arganil foram queimados 130,69\% da área florestal e, em Góis, 106,63\% (Lourenço, 1988).

A sobreposição, num único mapa, de todas as áreas queimadas no período compreendido entre 1975-2012, o último ano para que há cartografia disponível, torna a leitura difícil, razão que nos levou a separá-las pelas quatro décadas (fig. 2).

Assim, os primeiros grandes incêndios, na área em análise e com registo cartográfico, ocorreram no ano de 1975, nos concelhos de Pampilhosa da Serra e Arganil (fig. 2-A), onde, além da floresta, queimaram casas na aldeia de Cepos (concelho de Arganil), embora haja registos de incêndios anteriores na região, como o de 1961 (Lourenço, 2009, p. 9), que destruiu completamente a aldeia de Vale do Rio, no concelho de Figueiró-dos-Vinhos, a sul da área de estudo.

Mas, o primeiro incêndio que na serra do Açor reduziu a cinzas uma área superior a 10000 ha (fig. 1-B), mais precisamente 10 927ha (Viegas, Lourenço et al., 1988), teve lugar no mês de setembro de 1987, quando cercou 25 aldeias, de entre as quais o Piódão (concelho de Arganil) e a Gramaça (concelho de Oliveira do Hospital), e contornou mais de uma dúzia de outras, como foi o caso de Aldeia das Dez e Chão Sobral (concelho de Oliveira do Hospital), quatro das aldeias escolhidas para o estudo.

Três anos depois, em 1990, manifestou-se outro violento incêndio nos concelhos de Pampilhosa da Serra e Góis (fig. 2-B), tendo cercado as povoações de Malhada e Soito (concelho de Góis), onde, apesar dos esforços dos bombeiros, arderam algumas moradias.

Mais recentemente, no ano de 2005, um enorme incêndio, com 15837 ha, voltou a devastar parte da área queimada em 1987 (Lourenço, 2007) e, além da habitual destruição da vegetação, voltou a cercar várias aldeias, entre as quais as já mencionadas do Piódão (concelho de Arganil), Gramaça e Chão Sobral (concelho de Oliveira do Hospital).

No ano de 2012, houve um novo incêndio, desta vez ao redor de Rio de Mel (concelho de Oliveira do Hospital) (fig. 2-D), tendo atingido casas situadas na interface urbano-florestal.

As oito aldeias selecionadas para desenvolver investigação de campo localizam-se nas serras de xisto da Cordilheira Central portuguesa (fig. 1), na parte oriental do distrito de Coimbra, e, apesar de uma ou outra nuance específica, são representativas das aldeias afetadas por incêndios florestais nas áreas montanhosas de Portugal, dado que, nos últimos quarenta anos, todas elas foram tocadas ou cercadas por incêndios florestais e, algumas delas, por mais do que uma vez.

Assim, a escolha destas aldeias baseou-se em vários aspetos dos quais:

a) Cobertura de um período temporal relativamente longo, ou seja, desde que os incêndios florestais começaram a ser um problema grave em Portugal;

b) Marcas deixadas no ambiente físico e, em particular, nas áreas de interface urbano-florestal, por incêndios de grande severidade; 
c) Recorrência de ignições que provocaram grandes incêndios florestais, alguns deles catastróficos.

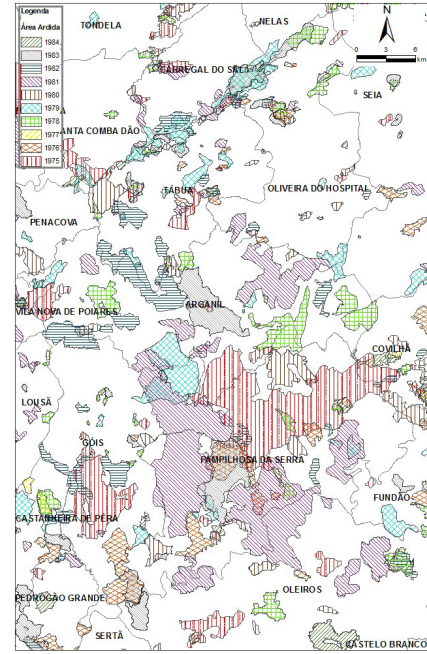

A

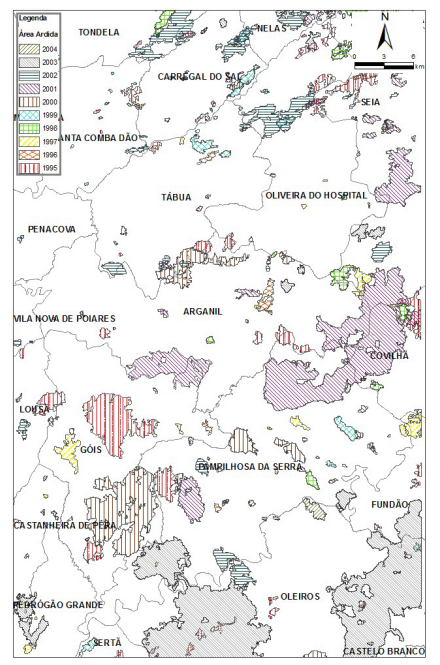

C

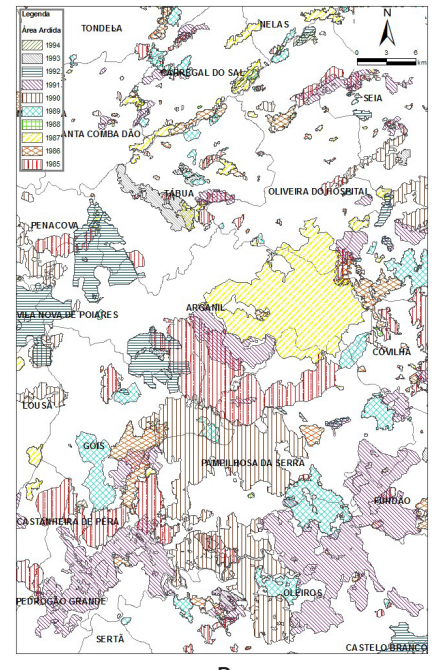

B

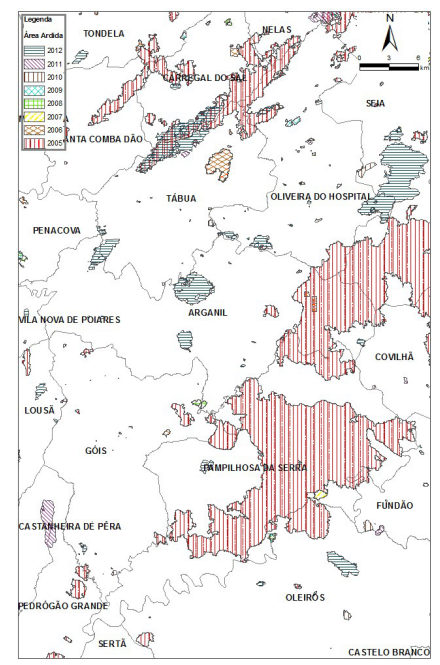

D

Fig. 2 - Distribuição dos incêndios florestais, nos municípios estudados da serra do Açor: A de 1975 a 1984; B - de 1985 a 1994; C - de 1995 a 2004 e D - de 2005 a 2012.

(Cartografia elaborada por Sofia Bernardino: até 1980, com base em Sofia Oliveira (2008) e arquivo do NICIF; depois de 1980, com base nos dados oficiais do ICNF).

Deste modo, no concelho de Arganil, foram selecionadas as aldeias de Cepos e Piódão; no concelho de Góis, as aldeias da Malhada e do Soito e, no concelho de Oliveira do Hospital, as aldeias da Gramaça, Chão Sobral, Aldeia das Dez e Rio de Mel (fig. 1) para nelas buscar a vocalização direta 
dos idosos, personagens centrais do lugar e parcela expressiva da população local, que não só ouviu falar dos incêndios, mas também participou diretamente dos acontecimentos.

\section{Conclusão}

A abordagem geográfica realizada foi de imprescindível valor para propiciar a identificação das aldeias mais suscetíveis aos incêndios florestais, nas quais os investigadores puderam, depois, interagir com a comunidade local para a realização do estudo sociológico, confirmando haver ali a ideia de lugar, isto é, um processo social de territorialização, com forte vinculação identitária e moldado por um tempo histórico consideravelmente longo, uma vez que, muitas delas, remontam a várias centenas de anos.

Em todas elas se identificou um progressivo abandono dos campos em socalcos mais afastados das aldeias, por opção dos proprietários, pois a grande maioria deles encontra-se em idade avançada (com mais de 60 anos), o que apenas lhes permite cultivar as áreas mais próximas de suas casas (Lourenço, 2006).

Deste modo, com o declínio da atividade agrícola, o mosaico parcelário das áreas rurais empobreceu-se e os campos em socalcos, abandonados, propiciam um acréscimo da carga combustível, que, por sua vez, aumenta os riscos de ignição e de propagação de incêndios, pelo que a serra do Açor constitui um bom caso de estudo, materializado nas oito aldeias selecionadas.

\section{Referências bibliográficas}

Lourenço, Luciano (1988) - Incêndios florestais entre Mondego e Zêzere no período de 1975 a 1985. Cadernos de Geografia, Coimbra, 7, 181-189.

Lourenço, Luciano (coord) (2006) - Paisagens de Socalcos e Riscos Naturais em Vales do Rio Alva. Coletâneas Cindínicas VI. Núcleo de Investigação Científicas de Incêndios Florestais. Coimbra, 202 p.

Lourenço, Luciano (2007) - Riscos Ambientais e Formação de Professores. Colectâneas Cindínicas VII, Núcleo de Investigação Científica de Incêndios Florestais da Faculdade de Letras da Universidade de Coimbra, Coimbra, 223 p.

Lourenço, Luciano (2009) - "Plenas manifestações do risco de incêndio florestal em serras do Centro de Portugal. Efeitos erosivos subsequentes e reabilitações pontuais”. Territorium, Revista da Associação Portuguesa de Riscos, Prevenção e Segurança, Lousã, n 16, p. 5-23;

Viegas, D. Xavier; Lourenço, L.; Neto, Luís; Pais, T.; Monteiro, J. P.; Ferreira, A. e Goulão, M. (1988) - Análise do Incêndio Florestal ocorrido em Arganil/Oliveira do Hospital de 13 a 20 de Setembro de 1987. Centro de Mecânica dos Fluidos, Coimbra, 102 p. 